\title{
DEBATE
}

\section{Problema de Saúde Pública: caracterizando e avaliando aplicações}

Aguinaldo Gonçalves

Grupo de Saúde Coletiva Epidemiologia e Atividade Física

FEF/Unicamp aguinaldo@fef.unicamp.br
O Editor deste periódico, no respectivo texto de apresentação, manifesta a legítima expectativa de que o debate aqui iniciado por Costa e Victora (2006) sobre o conceito de "Problema de Saúde Pública" (PSP) possa provocar contribuições a respeito por parte dos leitores. Assim posto, pareceu-nos que a recuperação de abordagens e aplicações do mesmo em diferentes segmentos do campo da Saúde Coletiva venha atender ao repto expressado. Nesse sentido, apresenta-se a seguir breve relato bibliográfico de experiência efetivada quando da sistematização em nosso meio do âmbito da Dermatologia Sanitária, bem como indagando-lhe soluções.

De fato, foi possível dimensionar, exploratória e pioneiramente, significado e impacto populacionais das principais afecções dessa área de conhecimento e intervenção em Saúde (síndrome de imunodeficiência adquirida-AIDS, doenças sexualmente transmitidas -DST, hanseníase, leishmanioses e ectoparasitoses tropicais) recorrendo-se basicamente aos critérios de PSP correntes em nosso meio já na formação dos sanitaristas, de magnitude, transcendência e vulnerabilidade.

$\mathrm{O}$ primeiro refere-se à abrangência, ao alcance, ao vulto que a moléstia atinge na população; corresponde, portanto, em termos amplos, à extensão do contingente de pessoas acometidas por sua ocorrência; lança-se mão, então, basicamente do emprego de indicadores epidemiométricos, como as taxas de prevalência e de incidência. Em relação à transcendência, entende-se como sendo o custo pessoal e social dos agravos à população, ou seja, atinência ao coletivo envolvido: tudo da relação saúde-doença-intervenção que passa a interferir diretamente nas relações sociais, econômicas, profissionais e culturais. $\mathrm{O}$ último critério utilizado, a vulnerabilidade, corresponde a quanto a afecção pode ser controlada mediante aplicações de investimentos e de conhecimentos específicos; em outras palavras, o quanto de possibilidade existe para que se consiga bloquear sua evolução em patamares mais restritos e desejáveis, com adoção de medidas apropriadas (Gonçalves, 1997).

Já no início dos anos oitenta, quando se observou o surgimento a nível populacional da AIDS e as discussões sobre tratar-se ou não seu controle de uma prioridade para o setor saúde, chegou-se a busca de decisões consistentes pela aplicação dessa tríade (Gonçalves; Gonçalves, 1985). Em termos de magnitude, chamava a atenção a velocidade evolutiva dos casos conhecidos: de todo o contingente registrado até então a nível nacional, metade o fora em três anos e a outra metade em três meses. A transcendência se conotava pelo alto predomínio dos doentes entre jovens em pleno vigor da idade economicamente produtiva e, complementarmente, com $100 \%$ de letalidade estimada à época, nos primeiros cinco anos após o diagnóstico. Otimisticamente, apontava-se a favor de sua vulnerabilidade a singularidade dos efeitos da Educação em Saúde na direção da monogamia e do sexo protegido entre homossexuais.

Também à época miraram-se as DST com o mesmo referencial (Gonçalves; Gonçalves, 1987). Especificamente, para a gonorréia relatava-se ocorrência anual só nos Estados Unidos de um milhão de casos novos e a perspectiva de dobro dessa cifra para o ano seguinte, lamentando-se a inexistência de dados dessa natureza para a realidade brasileira (por não ter merecido importância destacada pelos dirigentes setoriais de então), com exceção para alguns números de serviços universitários especializados, um paulista e outro gaúcho. Caracterizava-se, no tocante à transcendência, que uma, em cada duas mulheres recentemente infectadas, desenvolvia a doença sintomática, freqüentemente seguida de seqüelas graves, geralmente inflamação pélvica. Talvez pela perspectiva pessimista da provável não vulnerabilização da moléstia pela adoção dos procedimentos correntes, tinha-se agregado outro critério na identificação aí empreendida de PSP: a avaliação de possíveis perspectivas e cenários baseada na 
gestão institucional interna de ciência de tecnologia. Neste sentido, para o caso, deplorou-se "o fosso tecnológico existente entre os programas de pesquisa avançada e as realidades clínicas de outro lado, quase tão notável nos países industrializados que nos em desenvolvimento", pois "mesmo em certos países desenvolvidos, os serviços de controle de DST, até o presente, não contam com recursos senão de um laboratório periférico".

Prosseguindo pela entidade de maior significado social no interior da área, igualmente dirigiu-se a aplicação de tais critérios para a hanseníase (Gonçalves, 1987). Seqüencialmente, notou-se o destaque conferido à prevalência da mesma no país, situando-a em primeiro posto nas Américas e, em segundo, a nível internacional; a seguir, sua cronicidade e potencial de geração de incapacidades físicas, que, além de geralmente extensas, localizam-se em segmentos corpóreos estratégicos para a vida de correlação, isto é, em face, mãos e pés; finalmente, deploravam-se os insucessos acumulados até então no que se referia a imunização, diagnóstico precoce e tratamento adequado.

Para analisar as leishmanioses e as ectoparasitoses tropicais como PSP, Gonçalves et al. (1995) persistiram na adoção explícita das categorias em pauta, pontuando quanto às primeiras: i) a existência de milhares de casos no território nacional em período decenal; ii) o predomínio na sua evolução, de graves mutilações faciais e iii) a baixa eficácia dos respectivos tratamentos medicamentosos disponíveis; nas segundas, consideraram respectivamente: i) a extensa quantidade de por- tadores; ii) as repercussões imunológicas sistêmicas, como o aumento dos níveis das imunoglobulinas na escabiose e as positividades reacionais intra-dérmicas das dermatofitoses, no plano individual e, no coletivo, a associação com más condições sociais que facilitam a disseminação e o aparecimento das complicações e iii) as limitações terapêuticas, destacadamente indicação errônea, insuficência de administração e preço elevado.

Passados os anos que nos separam dessas iniciativas, vem a pergunta que não se cala: e ainda assim, por que, malgrado nossa perspicuidade 'nosográfica' com os PSP, continuamos a conviver com a extensão, gravidade e permanência dessas enfermidades? Em outros termos, porque mesmo lutando contra os PSP não conseguimos nos livrarmos deles?

Parece que se trata de retomar a questão enfocada pouco acima quando se mencionou a introdução do quarto critério para melhor se poder dimensionar as DST: naquela oportunidade se verbalizou avocando a figura do "fosso tecnológico" entre pesquisa e respostas às demandas sociais. Mesmo há não mais que dias, Morel (2006) reiterou tantos de nós expressando problema e resposta a esse desafio, pelo diagnóstico que "o país não investiu em Educação o necessário para usufruirmos da economia do conhecimento, nem para diminuirmos a iniqüidade que nos divide e tampouco logrou desenvolver uma política industrial que articulasse a academia, o governo e o setor produtivo." Vale dizer, para nos aproximarmos dos PSP em combate vitorioso, o caminho saudável não é nos concentrarmos só neles!

\section{Referências}

1. Costa JSD, Victora CG. O que é "um problema de saúde pública"? Rev Bras Epidemiol 2006; 9(1): 144-6.

2. Gonçalves A, et al. Saúde Coletiva e Urgência Em Educação Física e Esportes. Campinas: Papirus; 1997.
3. Gonçalves A, Gonçalves NNS. Síndrome de imunodeficiência adquirida. Agenda epidemiológica 1985; 2(4): 3-5.

4. Gonçalves A, Gonçalves NNS. As doenças de transmissão sexual como um problema de saúde pública no Brasil. Rev. Hosp. Cli. Fac. Med. USP 1987; 42(4): 185-189. 
5. Gonçalves A. Epidemiologia e controle da hanseníase no Brasil. Bol Sanit Panam. 1987; 102(3): 246-56.

6. Gonçalves A, Gonçalves NNS, Correa- Filho HR. Dermatologia Sanitária: estado atual e demandas de investigação. Interciência 1995; 20(5):265-8.
7. Morel CM. Inovação em saúde e doenças negligenciadas. Cad Saúde Pública 2006; 22(8): 1522-3.

\section{Resposta aos comentários do Prof. Aguinaldo Gonçalves}

Juvenal Soares Dias da Costa e Cesar G. Victora

Em reposta aos comentários do Prof. AguinaldoGonçalves, gostaríamos de reiterar que nosso artigo tinha como propósito delimitar ou tentar definir o difundido emprego da expressão "problema de saúde pública” em teses ou dissertações acadêmicas. Tanto que mencionamos que os princípios constitucionais que asseguram saúde como direito de cidadania desloca do campo dos serviços a priorização tradicional de agravos no enfoque de magnitude, transcendência e vulnerabilidade.

Contudo, o Professor Aguinaldo formula a questão: porque mesmo lutando contra os problemas de saúde pública não conseguimos nos livrar deles? Na verdade, vinte anos após a democratização do país e dezoito anos após a promulgação da Constituinte tem se observado profundas alterações no quadro epidemiológico do país.
Se por um lado, a mortalidade infantil tem declinado e as doenças passíveis de controle por imunizações tiveram suas incidências diminuídas, as transições: epidemiológica, nutricional e demográfica têm revelado um novo cenário. Assim, o predomínio das doenças crônicas não transmissíveis, o observado aumento dos níveis de sobrepeso e de obesidade e do crescimento do percentual de idosos na pirâmide populacional brasileira, respectivamente exigirão notáveis modificações e adaptações da sociedade. Tais ações exigirão políticas e articulações notadamente intersetoriais, que evidentemente necessitarão a inclusão de modificações tecnológicas nos serviços de saúde.

Portanto, concordamos com as colocações do Professor Aguinaldo quanto a necessidade de superação do "fosso tecnológico” existente entre pesquisa e respostas às demandas sociais e nos aliamos quanto à afirmação da necessidade dos investimentos em educação que propiciariam ao nosso ver no caminho da superação das desigualdades abismais no nosso país. 